\title{
Meme Kanseri Etiyolojisi ve Risk Faktörleri
}

\author{
Etiology and Risk Factors of Breast Cancer
}

\section{Aylin AÇIKGÖZ1', Emine AKAL YILDIZ²}

${ }^{1}$ Dr.Dyt., Hacettepe Üniversitesi, Sağlık Bilimleri Fakültesi, Beslenme ve Diyetetik Bölümü, Ankara

${ }^{2}$ Doç.Dr., Hacettepe Üniversitesi, Sağlık Bilimleri Fakültesi, Beslenme ve Diyetetik Bölümü, Ankara

\section{öz}

Meme kanseri, dünya genelinde ikinci sırada en sık görülen kanser iken, kadınlar arasında en sık görülen kanser türüdür. Hem gelişmiş hem de gelişmekte olan ülkelerde kadınlar arasında kansere bağlı ölüm nedenlerinde de ilk sırada yer almaktadır. Etiyolojisi çok faktörlüdür ve meme kanseri gelişimindeki birçok majör risk faktörü reprodüktif ve genetik gibi kolayca değiştirilemeyen değişkenlerdir. Değiştirilebilir faktörlerin belirlenmesi ve risk grupları için etkili tarama uygulamaları meme kanseri insidansını azaltıcı stratejilerinin geliştirilmesine katkı sağlayabilir. Bu derlemenin amacı, meme kanseri etiyolojisi ve risk faktörlerinin güncel literatür ile incelenmesidir.

Anahtar Kelimeler: Meme kanseri, Risk faktörleri, Antropometri

\section{A B S T R ACT}

Breast cancer is the second most common type of cancer around the world and also the most common cancer among women. It is in the first rank among causes of death due to cancer among women both in developed and developing countries. Its etiology is multifactorial and many of the major risk factors for breast cancer development are not easily modifiable, including reproductive and genetic variables. Identification of modifiable factors and effective screening practices for risk groups may contribute to development of prevention strategies decreasing breast cancer incidence. The aim of this review is to examine the etiology of breast cancer and risk factors with current literature.

KeyWords: Breast cancer; Risk factors; Anthropometry 
Kanserlerin hemen hepsi tek bir hücrenin, normal büyüme ve replikasyon süreçlerindeki kontrolünü kaybetmesi ile ortaya çıkmaktadır. Karsinogenez; başlangıç, ilerleme ve gelişme evreleri olmak üzere 3 evrede gerçekleşmektedir. Başlangıç evresi; hücrenin bir ajana maruz kalması ile sonuçlanan ilk genetik mutasyon ile oluşmaktadır. Ancak bu durum kanserin gelişimi için yeterli değildir. Başlangıç hücresi, hücresel proliferasyona neden olan gelişmiş ajan ile aktive edilmiş olmalıdır ve bu evre ilerleme evresi olarak adlandırılmaktadır. Gelişme evresinde ise başlangıç ve ilerleme evresinde oluşan hücreler tümör kütlesini oluşturmaktadır. Karsinogenezin sonunda hücre; bağımsız büyüme sinyali, büyüme karşıtı sinyallerin duyarsızığı, apoptozdan kaçınma, anjiogenezin sürdürülmesi, doku invazyonu ve metastaz gibi kanser hücresinin karakteristik özelliklerinin bazılarına veya hepsine sahip olabilmektedir. Besin, beslenme ve fiziksel aktivite ile ilişkili faktörler karsinogenezin de dahil olduğu birçok hücresel süreci etkileyebilmektedir (Roberts, 2010). Dünya Kanser Araştırma Fonu ve Amerikan Kanser Araştırmaları Enstitüsü 2007 yılında katılıkları panelde kanserin önlenmesinde besin, beslenme ve fiziksel aktivitenin rolü ile ilişkili bildiri yayınlamışlardır (Bkz. Şekil 1) (Glade, 2008). Bu derlemenin amacl, meme kanseri etiyolojisi ve risk faktörlerinin güncel literatür ile

\section{Risk Faktörleri}

Aile öyküsü meme kanserinin kalıtımsal faktörleri ile ilişkilendirilmekte ve vakaların \%5-15'inden sorumlu tutulmaktadır. Menstrüel ve üreme ile ilişkili faktörler \%25 oranında katkı sağlamaktadır. Birlikte düşünüldüğünde değiştirilemeyen faktörler olarak değerlendirebileceğimiz bu klasik risk faktörlerinin, vakaların \%30-40'ından sorumlu olduğunu söyleyebiliriz. Değiştirilebilir çevresel faktörlerin ise, \%60-70'lik orana sahip olduğu görülmektedir. Diyet ise, bu faktörler arasında en önemlilerindendir. Diyetsel faktörlerin meme kanseri riskini azaltıcı etkisinin \%30-35'lere ulaştığı kabul edilmektedir (Alvaro Luis Ronco \& De Stéfani, 2011). Meme kanserinin bilinen risk faktörleri Şekil 2'de verilmiştir.

\section{Cinsiyet ve Yaş}

Erkeklerle karşılaştırıldığında, kadınların yaşam boyu meme kanserine yakalanma riski yaklaşık 100 kat daha yüksektir. Kadın birey olmanın dışında, artan yaş en önemli risk faktörüdür. Otuz yaşında bir kadının önündeki 10 yıl süresince meme kanseri olma olasılığı 1/250 iken, bu oran 70 yaşındaki bir kadın için 10 kat artmakta ve 1/27'e yükselmektedir (Altekruse et al., 2010).

\section{Genetik Yatkınlık veya Aile Öyküsü}

Aile öyküsünde meme kanseri varlığı, bireyin özgeçmişinde invazive meme kanseri, duktal karsi-

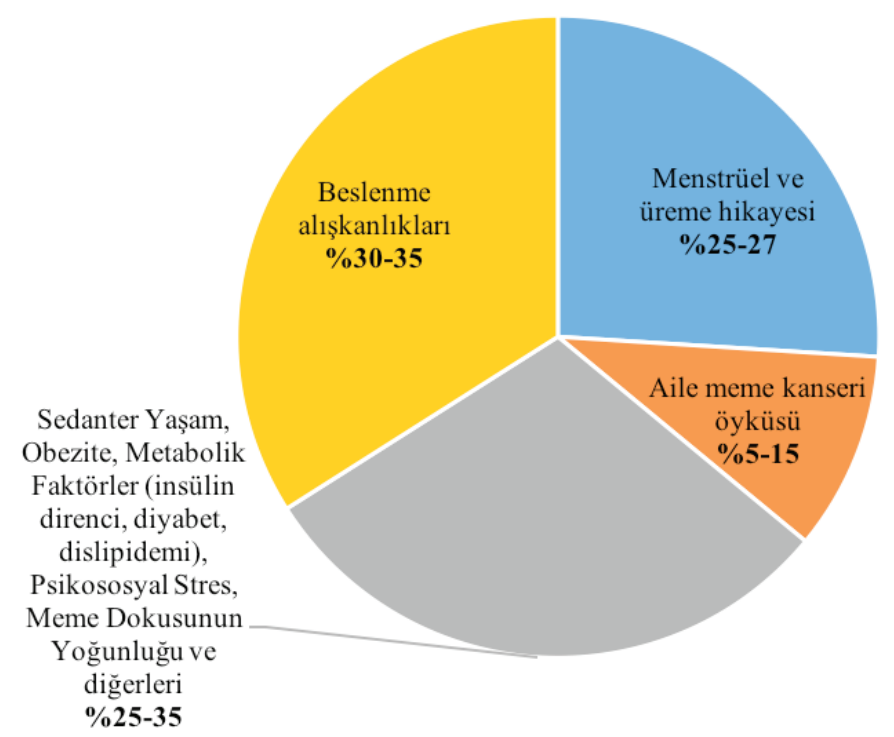

Şekil 1. Besin, Beslenme, Obezite ve Fiziksel Aktivitenin Meme Kanserinde Hücresel Süreçler Üzerine Etkileri (Glade, 2008) Şeklin görüntü kalitesi düşük, kalitesi iyileştirilmeli. 


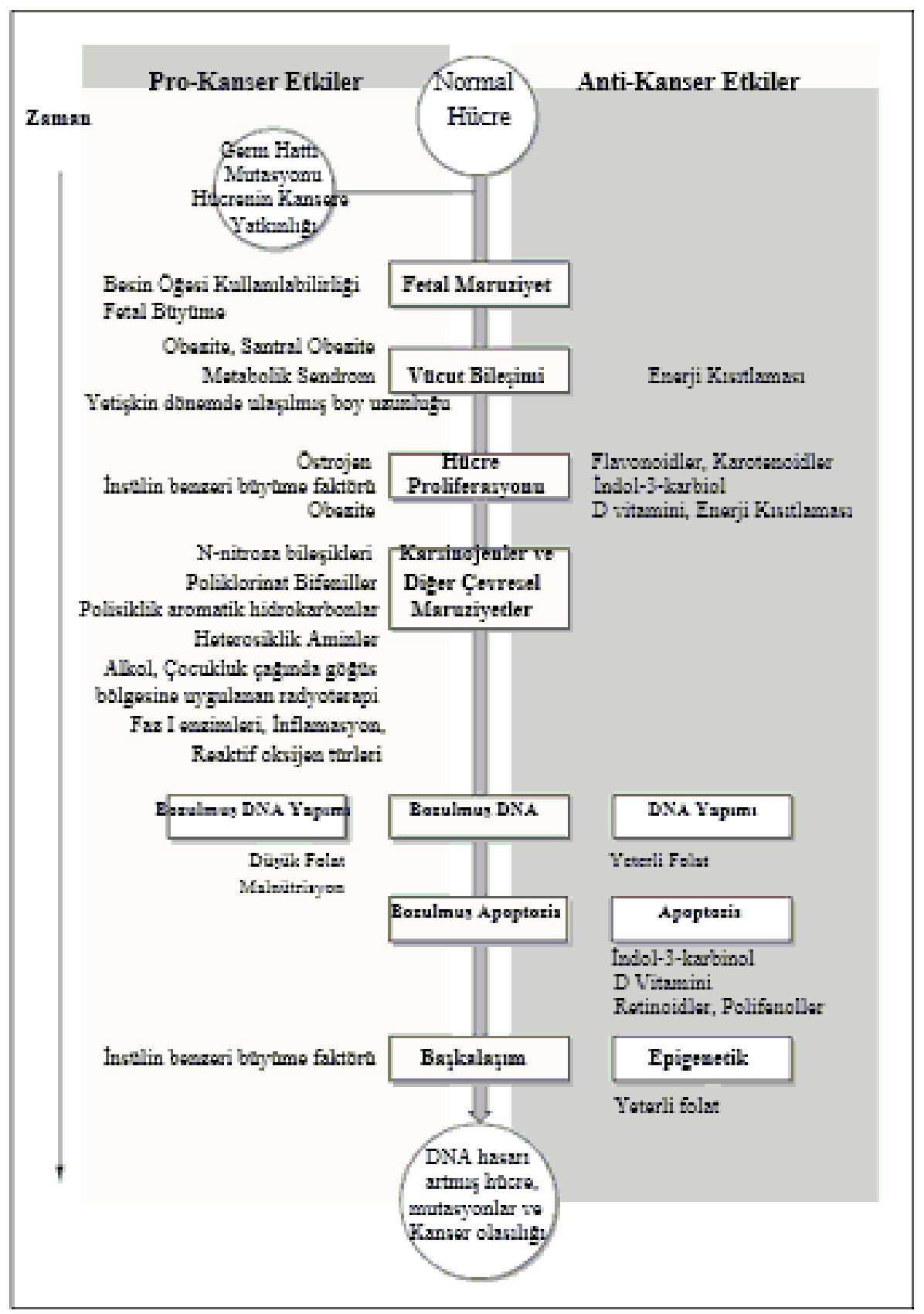

Şekil 2. Meme Kanserinin Bilinen Risk Faktörleri

nom in situ veya lobuler karsinom in situ varlığı veya benign proliferatif hastalık göstergesi olan meme biyopsilerinin varlığı da meme kanseri riskini artırmaktadır (http://www.ncbi.nIm.nih.gov/ pubmedhealth/PMH0032634). Yapılan bir metaanalizde, ailedeki herhangi bir akrabada meme kanseri öyküsünün varlığı 1.9, birinci derece akrabada 2.1, annede 2, kız kardeşte 2.3 kat riski artırıcı bir faktörken, kızında olması durumda 1.8, anne ve kız kardeşinde birlikte olma durumda 3.6 kat riski artırıcı bir faktör olarak bildirilmiştir. Ayrıca ikinci derece akrabada bulunması durumunda ise 1.5 kat meme kanserini artırıcı bir faktör olduğu vurgulanmıştır (Pharoah, Day, Duffy, Easton, \& Ponder, 1997). Meme kanserli hastaların \%510'unun BRCA1 ve BRCA2 genlerinde germ hattı mutasyonu görülebilmektedir. BRCA1 ve BRCA2 mutasyonuna sahip kadınların hayat boyu meme 
kanseri riskinin \%40-85 olduğu belirtilmektedir (Frank et al., 1998).

\section{Menarj, Menopoz, Doğum Yaşı ve Laktasyon}

Erken menarj, geç menopoz gibi endojen östrojene maruziyeti artıran üreme faktörleri ve menopoz sonrası kullanılan östrojen-progesteron hormonlarının kombinasyonu meme kanseri riskini artırmaktadır (Brinton, Schairer, Hoover, \& Fraumeni, 1988; Key, Appleby, Barnes, \& Reeves, 2002). Menarj yaşı 11 ve altında olan kadınların, 14 ve üstü olanlara göre meme kanseri riskinin \%20 yüksek olduğu bildirilmiştir (Brinton et al., 1988). Bu durumun nedenini açıklayan birçok mekanizma mevcuttur. Ancak tümü, hayat boyu artmış endojen hormonlara maruziyet ile ilişkilendirmektedir. Epidemiyolojik veriler, hayat boyu östrojen maruziyetinin özellikle Östrojen Reseptörü Pozitif [ER (+)] meme kanserleri için önemli bir risk faktörü olduğunu göstermektedir (Hiatt et al., 2014). Kısaca mensturasyondaki erken başlangıç yaşam süresince östrojene maruziyetin artması ile ilişkilidir (Ban \& Godellas, 2014). Menopoza giriş yaşında her geçen yılın, meme kanseri riskini \%3 artırdığı belirtilmektedir (Trichopoulos, MacMahon, \& Cole, 1972). Premenopozal kadınların aynı yaştaki post-menopozal kadınlara göre meme kanseri riskinin, özellikle ER (+) tümörler için, 1.43 kat daha yüksek olduğu belirtilmiştir (Cancer, 2012). Yirmi yaş öncesinde gebelik sürecinin tamamını geçiren kadınlarda, meme kanseri riskinin daha düşük olduğu bilinmektedir. Otuz beş yaş sonrası doğum yapan kadınlarda ise, hiç doğum yapmamış kadınlara kıyasla meme kanseri riskinin yaklaşık \%50 daha düşük olduğu belirtilmektedir (http://www. ncbi.nlm.nih.gov/pubmedhealth/PMH0032634). Ayrıca emzirme meme kanseri riskini azaltıcı bir faktör olarak değerlendirilmektedir. Her 12 aylık emzirmenin meme kanseri riskinde \%4.3 azalma sağladığı ve her ilave doğum için ise bu orana \%7 eklenebileceği belirtilmektedir (Cancer, 2002).

\section{Oral Kontraseptif Kullanımı ve Hormon Replasman Tedavisi}

Ban ve Godellas (Ban \& Godellas, 2014) çalışmalarında, oral hormonal menopoz tedavisi kullanımının meme kanseri riski üzerine olan etkisinin tedavinin süresi ile de ilişkili olduğunu belirtmiş ve 5 yıllık kullanımın \%15, 10 yıllık kullanımın ise
\%34 oranında meme kanseri riskini artırdığını vurgulamıştır. Oral kontraseptiflerin kullanımı ve meme kanseri riski arasındaki ilişkiyi araştıran çaısşmaların sonuçları farklılık göstermektedir (Kaminska, Ciszewski, Lopacka-Szatan, Miotla, \& Staroslawska, 2015). Yapılan bazı çalışmalarda kullanım durumunun riskte artışa neden olabileceği gösterilirken (Collaborative, 1996; Pike, Krailo, Henderson, Duke, \& Roy, 1983), bazı çalışmalarda ilişki saptanmadığı belirtilmiştir (Casey, Cerhan, \& Pruthi, 2008; Westhoff, 1999). Sonuçlardaki bu farklıığın nedeni olarak; oral kontraseptiflerin içeriğinde zamanla gerçekleşen değişim gösterilmektedir (Kaminska et al., 2015).

\section{Obezite}

Obezitenin meme kanseri riski üzerine olan etkileri menopozal durumdan etkilenmektedir. Menopoz öncesi yüksek beden kütle indeksinin (BKi) anlamlı şekilde koruyucu etkisi bulunmakta iken, menopoz sonrası meme kanseri riski ile pozitif korelasyon göstermektedir. Obez premenopozal kadınların normal ağırlıktakilerle karşılaştırıldığında meme kanseri riski yarım kat daha fazla iken, post-menopozal kadınlarda bu oran \%25'dir (Van den Brandt et al., 2000). Prospektif gözlemsel çaIışmalardan oluşan bir meta-analizde ise, BKi'deki her $5 \mathrm{~kg} / \mathrm{m}^{2}$ lik artışın post-menoposal meme kanseri riskinde \%12 artışa neden olduğu bildirilmiştir (Renehan, Tyson, Egger, Heller, \& Zwahlen, 2008). Benzer olarak, Suziki ve ark. (Suzuki, Orsini, Saji, Key, \& Wolk, 2009) yayınladıkları meta-analizde obez post-menopozal ER/PR (-) kadınlarda meme kanseri riskinin \%80 daha yüksek olduğunu bildirmiştir. Adipoz dokuda aromataz enzimler tarafından androjenlerin östrojene dönüşümünün dolaşımdaki östrojenin artışına bağlı olarak post-menopozal kadınlarda meme kanseri riskini artırdığına dair hipotez mevcuttur (Toniolo et al., 1995). Premenopozal obez kadınlarda serum östradiol seviyesinde düşme söz konusudur, bu durum adipoz dokudaki artışın koruyucu etkisini açıklamaktadır (Potischman, Christine, Swanson, \& Hoover, 1996). Bunun yanı sıra, adölesan ve yetişkin yaşlardaki ağırlık kazanımı meme kanseri riski ile ilişkilendirilmektedir. Bir kadının vücut gelişiminin gerçekleştiği yaş olan 18 yaştaki ağırlık kazanımının meme kanseri riskinde artışa neden olduğu belirtilmiştir (Barnes-Josiah, Potter, Sell- 
ers, \& Himes, 1995). Başka bir çalışmada ise, sadece 2 kg'ık artış ile karşılaştırıldığında 25 kg'ık bir ağırlık kazanımının meme kanseri riskini iki kat artırdığı bildirilmiş, ancak bu durumun sadece menopoz döneminde hormon almamış kadınlarda gözlendiği belirtilmiştir (Huang ve ark., 1997). Ronco ve ark (Alvaro L Ronco, 2007) 18 yaş ile yetişkin dönem arasında, orta-yüksek sosyo-ekonomik düzeye sahip, 12 kg'dan fazla ağırlık artışı olan Uruguaylı kadınlarda, ağırlık kaybı olan veya <3 kg ağırlık artışı olanlarlara kıyasla, meme kanseri riskinin \%77 oranında artış gösterdiği bildirilmiştir. Genç yaşlardaki vücut yağ dokusu ve hayat boyu meme kanseri olma riski arasında güçlü ve bağımsız ters yönlü bir ilişki söz konusudur (Baer, Tworoger, Hankinson, \& Willett, 2010). Bu nedenle genel olarak yetişkinlik dönemine kadar gerçekleşen önemli ağırlık kazanımının risk artışı ile ilişki olduğu belirtilmektedir (Shi ve ark., 2010). Ek olarak normal vücut ağırlığın korunumu veya vücut ağırığı fazla ise azalmanın sağlanması da meme kanseri riskinde azalma ile ilişkili olduğu bildirilmiştir (Alvaro Luis Ronco \& De Stéfani, 2011).

Vücut yağının üst veya santral dağııımı insülin direnci, hiperinsülinizm, cinsiyet hormonu bağlayıcı globülin seviyelerinde azalma, androjenlerde ve aromatizasyonda artış gibi çoklu metabolik ve hormonal değişiklikler ile ilişkilidir (Ballard-Barbash, 1994). Bu nedenle, daha çok gelişmiş toplumları içeren uluslararası literatür, bu vücut bileşenlerine sahip kadınlarda, vücut yağının kalça ve alt ekstremitelerde yoğunlaşan kadınlara göre, meme kanseri riskinin yüksek olduğunu vurgulamaktadır (Alvaro Luis Ronco \& De Stéfani, 2011).

Bölgesel yağlanmanın değerlendirilmesinde bir ölçüt olan bel-kalça oranı ile meme kanseri riski arasındaki ilişkiyi araştıran çalışmalarda en tutarlı sonuçlar menopozal hormon tedavisi kullanmayan post-menopozal kadınlarda saptanmış ve artan bel-kalça oranı ile riskin arttığı belirtilmiştir (Li, 2010). Iowa Kadın Sağlığı Çalışması'nda hem BKi hem de 18 yaş sonrası gerçekleşen ağırlık değişiminin meme kanseri riski ile pozitif ilişkili olduğu, özellikle 65 yaş ve üstü en yüksek çeyreklikteki bel-kalça oranına sahip kadınlarda meme kanseri riskinin arttığı ve bu oranın 55-64 yaş, 65-74 yaş ve 75-84 yaş kadınlarda sırasıyla; 1.38 (GA:\%95, RR:1.1-1.8), 1.34 (GA:\%95, RR:1.2-1.6), 1.49 kat (GA:\%95, RR:1.2-1.9) yüksek olduğu belirtilmiş- tir (Sweeney, Blair, Anderson, Lazovich, \& Folsom, 2004). Yayınlanan bir meta-analizde, bel-kalça oranındaki her 0.1 birimlik artışın meme kanseri riskini \%19 artırdığı bildirilmiş ve bu durumun post-menopozal meme kanserinin nedeni olarak gösterilebileceği vurgulanmıştır (Marmot et al., 2007). Ahn ve ark (Ahn ve ark., 2007), menopozal hormon tedavisi kullanmayan bel-kalça oranı >0.94 olan kadınlarda, hormon kullanımı olan ancak bel-kalça oranı 0.70 olan kadınlarla karşılaştırıldığında, meme kanseri riskinin yaklaşık \%90 daha yüksek olduğunu bildirmiştir (RR1/4:1.88, 1.1-3.2, GA:\%95, p<0.001). Ancak aynı çalışmada, çalışma sürecinde hormon kullanan ve belkalça oranı >0.94 olan kadınlar referans grupla karşılaştırıldığında, meme kanseri riskinde anlamIı bir değişiklik görülmemiştir (RR1/4:1.00, 0.71.5, GA:\%95, p=0.18) (Ahn ve ark., 2007). Aynı zamanda obezitenin meme kanseri rekürensini \%35-40 oranlarında artırdığı ve düşük sağkalım ile ilişkili olduğu da belirtilmektedir (Jiralerspong and Goodwin 2016). Benzer şekilde 2016 yılında yayınlanan bir derlemede, erken tanı alan meme kanserli kadınlarda obezitenin ikincil kanserlerin riskinde de artışa neden olabileceği ve tanı sonrası ağırlık artışının toplam mortaliteyi de artırdığı belirtilmiştir (Yung and Ligibel 2016).

\section{Enerji Kısıtlaması}

Insan ve hayvan çalışmaları diyetsel enerji kısıtlamasının, dolaşımdaki insülin, leptin, cinsiyet hormonu bağlayıcı globülin, insülin benzeri büyüme faktörü-1, östradiol, testosteron, reaktif oksijen türlerinin seviyelerindeki uygun değişikliklerin yanı sıra adipokinlerin ve inflamatuar sitokinlerin salınımı ve üretimleri ile interlökin- 6 seviyesinde azalma sağlaması yoluyla meme kanseri riskine karşı koruyucu etkisi olduğunu göstermektedir (Harvie \& Howell, 2006). Enerji alımındaki \%1040'lık bir kısıtlama ile hücre proliferasyonunda azalma, anti-anjiojenik süreçler üzerinden apoptoziste artış olduğu gösterilmiştir (Fair \& Montgomery, 2009). Ek olarak; diyette enerji kısıtlaması sonucunda meme dokusunda lipid metabolizması ve glikolitik yolaklardaki genlerin ekspresyonunda azalma olduğu bildirilmiştir (Ong ve ark., 2009). Çalışmalarda diyetsel enerji kısıtlamasının hücre proliferasyonunu engellediği, proapoptotik bir çevre oluşturduğu ve premalignant ve malig- 
nant meme patolojilerine bitişik kan damarlarının yoğunluğunu azalttığı gösterilmiştir (Thompson, Zhu, \& Jiang, 2004). Insan ve hayvan çalışmalarından elde edilen veriler doğrultusunda, aralıklı yapılan enerji kısıtlaması ve ağırlık kaybının kanserden koruyucu etkisi nedeniyle önerilebilir. Aralıklı enerji kısıtlamasının (örneğin; haftanın bir günü, \%10-40 arasında), kronik bir enerji kısıtlamasına göre meme kanserini önlemede daha etkili olabildiği belirtilmektedir (Alvaro Luis Ronco \& De Stéfani, 2011).

\section{Metabolik Sendrom ve İnsülin Direnci}

Bazı çalışmalar metabolik sendrom bileşenlerinin de meme kanseri riski ile direkt ilişkili olduğunu belirtmektedir. Düşük HDL kolesterol, yüksek kan şekeri, yüksek trigliserit seviyesi, post-menopozal dönemde hafif şişman olma durumu, abdominal obezite, hipertansiyon, insülin, C-peptid ve insülin benzeri büyüme faktör-1 seviyelerinde yükseklik gibi tüm bileşenler meme kanseri riski ile ilişkilendirilmektedir (Alvaro Luis Ronco \& De Stéfani, 2011). Metabolik sendromla ilişkili metabolik ve hormonal faktörlerin, meme kanseri prognozunda da etkili olduğu bildirilmektedir (Pasanisi et al., 2006). Yapılan bir Avrupa çalışmasında metabolik sendrom tanılı, 50 yaş altı, yüksek BKi'ye sahip kadınlarda meme kanseri insidansı azalan meme kanseri riski ile ilişkilendirilirken, 60 yaş üstü kadınlarda meme kanseri mortalitesinde artış ile ilişkilendirilmiştir (Bjørge ve ark., 2010). Esposito ve ark (Esposito, Chiodini, Colao, Lenzi, \& Giugliano, 2012), 6417 kanser vakasını içeren 9 çaışmayı değerlendirdiklerinde metabolik sendrom ve post-menopozal meme kanseri riski arasındaki ilişkiyi incelemişler ve metabolik sendromun meme kanseri riskini \%52 oranında artırdığını bildirmişlerdir ( $p<0.001)$. Aynı meta-analizde yapılan üst analiz sonucunda metabolik sendromunun 5 bileşenin meme kanseri riski ile ilişkilendirilebileceği ve artan BKi/bel çevresinin \%12, hipergliseminin (yüksek açlık şekeri veya diyabet) $\% 19$, artan kan basıncının \%13, artan trigliserit seviyelerinin $\% 8$, düşük HDL seviyelerinin $\% 39$ oranında meme kanserinden sorumlu olabileceği belirtilmiştir (Esposito ve ark., 2012).

Yapılan bazı çalışmalar insülinin meme kanseri gelişiminde etkili olduğunu bildirmiştir (Kaaks, 1996). Pankreatik insülin üretiminin göstergesi olan serum C-peptid düzeyleri, post-menopozal kadınlarda artan meme kanseri riski ile ilişkilendirilmiştir (Verheus et al., 2006). Aynı zamanda yüksek serum insülin düzeyinin meme kanserli hastalarda kötü prognozla ilişkili olduğu belirtilmektedir (Goodwin et al., 2002). Insülinin gonadotropik etkisi ile androjenlerin üretimi için over stroması uyarılır. Androjenlerin periferal dokulardaki aromatizasyonu, menopoz sonrası östrojenin ana kaynağıdır (Nelson \& Bulun, 2001). Buna ek olarak insülin; aromataz aktivitesini de upregüle etmektedir (Grodin, Siiteri, \& MacDonald, 1973). Sonuç olarak; östrojen sentezinin düzenlenmesindeki iki önemli durum insülin ile uyarımaktadır. Östrojenin çoğu abdominal, meme, kalça ve uyluk bölgesindeki yağ dokusunda üretilmektedir (Cauley, Gutai, Kuller, LeDonne, \& Powell, 1989). Abdominal yağ dokusu, hem androjenler hem de östrojenin önemli kaynağıdır. Obez post-menopozal kadınlar yüksek düzeylerde östrojen üretirler, bu durum obezite ve meme kanseri arasındaki ilişkiye temel oluşturmaktadır (Agnoli ve ark., 2010). Insülinin aynı zamanda karaciğerde cinsiyet hormonu bağlayıcı globülinin üretimini azalttığı, böylece cinsiyet hormonu biyoyararlılığını arttığı ve metabolik sendromun meme kanseri riskindeki artış ile ilişkisinin dolaşımdaki hem total hem de serbest testosteron ile ilgili olduğu belirtilmektedir (Alvaro Luis Ronco \& De Stéfani, 2012).

\section{Radyasyon maruziyeti}

Medikal prosedürler de dahil olmak üzere radyasyon maruziyeti, meme kanseri riskini artırıcı bir faktör olarak bildirilmiştir (C. E. Land ve ark., 2003). Radyasyona maruz kalınan yaş önemlidir (C. E. Land ve ark., 2003). Land ve ark. (C. E. Land ve ark., 2003) 20 ve altı yaşlarda radyasyona maruz kalma durumunun, 40 yaş sonrası maruziyete göre daha yüksek riske sahip olduğunu bildirmiştir. Ancak genç yaşlarda yüksek dozda kümülatif maruziyetin riski artırdığını destekleyen veriler olsa da, düşük dozda göğüs bölgesine uygulanan radyografi veya mamografinin de meme kanseri riskini artırdığı bildirilmiştir (Ma, Hill, Bernstein, \& Ursin, 2008). Bu nedenle koruma veya tanı koyma amaçlı yapılan iyonize radyasyon uygulamalarında, seçici olunması, yararları riske ağır basıyorsa uygulanması önerilmektedir (Golubicic, Borojevic, \& Pavlovic, 2007). 


\section{Alkol ve Sigara Kullanımı}

Yüksek düzeylerde alkol tüketimi de meme kanseri riskini artırmaktadır. Vaka-kontrol ve kohort çalışmalarının dahil edildiği bir meta-analizde, hiç alkol tüketmeyen kadınlarla karşılaştırıldığında, her gün 35-44 g alkol tüketen kadınların $\% 32$, her gün en az $45 \mathrm{~g}$ alkol tüketen kadınların ise \%46'lık bir risk artışıyla karşı karşıya oldukları bildirilmiştir (Hamajima et al., 2002). Buna ek olarak; bu riskin lineer olduğu ve günlük eklenen her 1 porsiyon alkolün (10 g) riski \%7-9 oranında artırdığı belirtilmektedir (Hamajima ve ark., 2002; Smith-Warner ve ark., 1998).

Sigara kullanımı ve meme kanseri arasındaki ilişki ise belirsizliğini korumaktadır (Ban \& Godellas, 2014). Ancak sigara maruziyeti, özellikle yavaş asetilasyon $\mathrm{N}$-asetil transfferaz 2 genotipli premenopozal meme kanseri riskinde ılımlı bir artış ile ilişkilendirilmektedir (S. R. Land, Liu, Wickerham, Costantino, \& Ganz, 2014). Bazı çalışmalar özellikle erken yaşlarda başlayan, fazla miktarda ve uzun süre sigara kullanımının meme kanseri riskini artırdığını bildirmektedir (Cui, Miller, \& Rohan, 2006). Cerrahların Genel Raporu'na göre; aktif sigara kullanımının küçük, ancak anlamlı şekilde meme kanseri riskini artırdığı, pasif içiciliğin ise premenopozal kadınlarda meme kanseri riski ile ilişkili olabileceği belirtilmiştir (General,
2014). Benzer şekilde; yeni yayınlanan bir metaanalizde de, sigara kullanımının meme kanseri riskinde ılımlı bir artışa neden olduğu belirtilmiştir (RR:1.10, RR:1.08; sırasıly prospektif ve retrospektif çalışmalarda). Aynı çalışmada pasif sigara içiciliğinin de, birkaç yıl öncesine göre, meme kanseri riskini ılımlı şekilde artırdığı belirtilmiştir (RR:1.07, RR:1.30; sırasıyla prospektif ve retrospektif çalışmalarda) (Macacu, Autier, Boniol, \& Boyle, 2015).

\section{Fiziksel Aktivite}

Yapılan birçok çalışma meme kanseri riskini azaltmak için fiziksel aktivite önerisinde bulunmaktadır. Gözlemsel ve vaka-kontrol çalışmaları, orta şiddetli düzenli fiziksel aktivitenin meme kanseri riskini \%10-50 oranlarında azaltabileceğini bildirmektedir (Friedenreich, 2001; Kobayashi, 2012). Prospektif çalışmaları içeren bir metaanalizde, düzenli yapılan fiziksel aktivitenin meme kanseri riski üzerine daha ılımlı bir etkisi olduğu ve relatif riskin \%10-12 arasında düştüğünü belirtilmiştir. Bu durum doza bağlı bir etkinin varlığını gösterebilir. Aynı meta-analizde bu yararlı etkinin, normal ağırlıktaki premenopozal kadınlar ile ER/PR (-) kanserlerde daha anlamlı olduğu belirtilmiştir (Wu, Zhang, \& Kang, 2013) (Bkz. Tablo 2).

Tablo 1. Antropometrik faktörler ve meme kanseri riski arasındaki ilişki (Li, 2010)

\begin{tabular}{|c|c|}
\hline Risk Faktörü & Risk Değerlendirmesi Özeti \\
\hline $\begin{array}{c}\text { BKI, pre-menopozal kadınlar } \\
\text { Doz-yanıt etkisi } \\
\text { (eklenen her } 5 \text { kg/m2 BKI için) }\end{array}$ & \%15 azalan risk \\
\hline $\begin{array}{c}\text { BKI, post-menopozal kadınlar } \\
\text { Doz-yanıt etkisi } \\
\text { (eklenen her ilave } 5 \mathrm{~kg} / \mathrm{m} 2 \mathrm{BKI} \text { için) }\end{array}$ & \%12 artan risk \\
\hline $\begin{array}{l}\text { Ağırlık Değişimi, post-menopozal kadınlar } \\
\text { Doz-yanıt etkisi } \\
\text { (eklenen her ilave } 5 \text { kg ağırlık kazanımı için) }\end{array}$ & \% \% artan risk \\
\hline $\begin{array}{c}\text { Bel-kalça oranı } \\
\text { Doz-yanıt etkisi } \\
\text { (eklenen her ilave } 0.1 \text { birim bel-kalça oranı için) }\end{array}$ & \%19 artan risk \\
\hline $\begin{array}{l}\text { Boy, pre-menopozal kadınlar } \\
\text { Doz-yanıt etkisi } \\
\text { (eklenen her ilave } 5 \mathrm{~cm} \text { boy uzunluğu için) }\end{array}$ & \%9 artan risk \\
\hline $\begin{array}{c}\text { Boy, post-menopozal kadınlar } \\
\text { Doz-yanıt etkisi } \\
\text { (eklenen her ilave } 5 \mathrm{~cm} \text { boy uzunluğu için) }\end{array}$ & \%11 artan risk \\
\hline
\end{tabular}


Tablo 2. Fiziksel aktivite ve meme kanseri riski arasındaki ilişki (Li, 2010)

\begin{tabular}{cc}
\hline Risk Faktörü & Risk Değerlendirmesi Özeti \\
$\begin{array}{c}\text { Yüksek/düşük yaşam boyu aktivite } \\
(\$ 3 \text { saat/hafta/ inaktif } \$ 2 \text { saat/hafta })\end{array}$ & $\sim \% 20-40$ azalan risk \\
Doz-Yanıt Etki & $\sim \% 6$ azalan risk \\
(haftalık olarak eklenen her ilave 1 saat için $)$ & \\
\hline
\end{tabular}

Tablo 3. Meme kanseri riskini azaltıcı ve koruyucu faktörler (http://www.ncbi.nIm.nih.gov/pubmedhealth/PMH0032634)

\begin{tabular}{|c|c|}
\hline Risk Faktörleri & Koruyucu Faktörler \\
\hline Artan Yaş & Östrojen kullanımı (histerektomi sonrası) \\
\hline Aile sağlık öyküsü & Egzersiz \\
\hline $\begin{array}{l}\text { Germline kalıtım duyarlılığı } \\
\text { BRCA1, BRCA2 ve diğer meme kanseri } \\
\text { duyarlı genlerde mutasyon }\end{array}$ & Erken gebelik \\
\hline Alkol alımı & Emzirme \\
\hline Meme dokusu yoğunluğu (mamografik) & Selektif östrojen reseptör modülatörleri (SERMs) \\
\hline $\begin{array}{c}\text { Östrojen (endojen) } \\
\text { Menstrüel hikaye (erken menarj/geç } \\
\text { menopoz) } \\
\text { Nuliparite (Çocuk sahibi olmama durumu) } \\
\text { illk doğumun geç yaşta olması }\end{array}$ & Aromataz inhibitörleri veya inaktivatörleri \\
\hline $\begin{array}{c}\text { Hormon tedavisi hikayesi } \\
\text { Östrojen ve progesteron hormon replasman } \\
\text { tedavi kombinasyonu (HRT) }\end{array}$ & Risk azaltıcı mastektomi \\
\hline Obezite & Risk azaltıcı ooferektomi veya over ablasyonu \\
\hline \multicolumn{2}{|l|}{ Bireysel meme kanseri öyküsü } \\
\hline \multicolumn{2}{|l|}{$\begin{array}{l}\text { Bireysel benign meme hastalığının proliferatif } \\
\text { formlarının öyküsü }\end{array}$} \\
\hline Irk & \\
\hline Meme/göğüs bölgesine radyasyon maruziyeti & \\
\hline
\end{tabular}

\section{Diğer Faktörler}

Meme kanseri insidansı ve mortalite riski aynı zamanda coğrafi yapı, kültür, ırk, etnik köken ve sosyo-ekonomik durumda da farklılık göstermektedir. Diğer ırklarla karşılaştırıldığında, beyaz kadınlarda meme kanseri insidansı daha yüksektir. Ancak bu sonucun kanser taramalarına gösterdikleri ilgi nedeniyle olabileceği de belirtilmektedir (Tarver, 2012). 2004-2010 yılları arasında, yeni tanı almış meme kanserli bireylerin \%62'si beyaz iken, sadece \%52'sinin siyah ırkta olduğu bildirilmiştir. Mortalite oranlarına bakıldığında ise, siyah ırk beyaz ırkla karşılaştırıldığında daha yüksek mortalite oranına sahip olduğu belirtilmiştir (Altekruse ve ark., 2010). Bunun nedeni olarak da üçlü-negatif fenotip gibi kısmen olumsuz histolojik özelliklere sahip olmaları gösterilebilir (Bauer, Brown, Cress, Parise, \& Caggiano, 2007). Hem insidans hem de mortalite oranları karşılaştırıldığında, İspanyol/Asyalı/Pasifik Adalı kadınlarda, beyaz ve siyah kadınlara göre daha düşük oranlar görülmektedir (Altekruse et al., 2010). Düşük sos- 
yo-ekonomik durum ve düşük eğitim seviyesi de tarama yöntemlerine ulaşmayı zorlaştıran durumlar olması nedeniyle meme kanseri riskini artırıcı faktörler olarak belirtilmektedir (Bradley, Given, \& Roberts, 2002).

Meme kanserini azaltıcı ve koruyucu faktörler Tablo 3'da özetlenmiştir (http://www.ncbi.nlm. nih.gov/pubmedhealth/PMH0032634).

\section{SONUÇ}

Meme kanseri, dünya genelinde en sık görülen 2 . kanser iken, kadınlar arasında ise en sık görülen kanser türüdür. Hem gelişmiş hem de gelişmekte olan ülkelerde kadınlar arasında kansere bağlı ölüm nedenlerinde ilk sırada yer almaktadır. Etiyolojisi çok faktörlüdür ve başlıca genetik, epigenetik ve endokrin faktörler yer almaktadır ve birçoğu değiştirilemeyen faktörlerdir. Meme kanseri epidemiyolojisinin anlaşılması, etkili tarama uygulamaları ile yapılacak bilgilendirmeler, klinisyenlerin risk altındaki bireyleri değerlendirmeleri meme kanseri insidansında azalmanın sağlanmasında katkı sağlayabilir. Aynı zamanda obezite prevelansının azaltılması, sigara ve alkol kullanımının engellenmesi ve bireylerin fiziksel aktivite yönlendirilmesi meme kanseri riskinin azaltımasına yardımcı olabilir.

\section{KAYNAKLAR}

Agnoli, C., Berrino, F., Abagnato, C. A., Muti, P., Panico, S., Crosignani, P., \& et al. (2010). Metabolic syndrome and postmenopausal breast cancer in the ORDET cohort: a nested case-control study. Nutrition, Metabolism and Cardiovascular Diseases, 20(1), 41-48.

Ahn, J., Schatzkin, A., Lacey, J. V., Albanes, D., BallardBarbash, R., Adams, \& et al. (2007). Adiposity, adult weight change, and postmenopausal breast cancer risk. Archives of Internal Medicine, 167(19), 20912102.

Altekruse, S., Kosary, C., Krapcho, M., Neyman, N., Aminou, R., Waldron, \& et al. (2010). SEER cancer statistics review, 1975-2007. Bethesda, MD: National Cancer Institute, 7.

Baer, H. J., Tworoger, S. S., Hankinson, S. E., \& Willett, W. C. (2010). Body fatness at young ages and risk of breast cancer throughout life. American Journal of Epidemiology, 171(11), 1183-1194.

Ballard-Barbash, R. (1994). Anthropometry and breast cancer. Body size-a moving target. Cancer, 74(S3),
1090-1100.

Ban, K. A., \& Godellas, C. V. (2014). Epidemiology of breast cancer. Surgical Oncology Clinics of North America, 23(3), 409-422.

Barnes-Josiah, D., Potter, J. D., Sellers, T. A., \& Himes, J. H. (1995). Early body size and subsequent weight again as predictors of breast cancer incidence (lowa, United States). Cancer Causes \& Control, 6(2), 112-118.

Bauer, K. R., Brown, M., Cress, R. D., Parise, C. A., \& Caggiano, V. (2007). Descriptive analysis of estrogen receptor (ER)-negative, progesterone receptor (PR)negative, and HER2-negative invasive breast cancer, the so-called triple-negative phenotype. Cancer, 109(9), 1721-1728.

Bjørge, T., Lukanova, A., Jonsson, H., Tretli, S., Ulmer, H., Manjer, \& et al. (2010). Metabolic syndrome and breast cancer in the me-can (metabolic syndrome and cancer) project. Cancer Epidemiology Biomarkers \& Prevention, 19(7), 1737-1745.

Bradley, C. J., Given, C. W., \& Roberts, C. (2002). Race, socioeconomic status, and breast cancer treatment and survival. Journal of the National Cancer Institute, 94(7), 490-496.

Brinton, L. A., Schairer, C., Hoover, R. N., \& Fraumeni, J. F. (1988). Menstrual factors and risk of breast cancer. Cancer Investigation, 6(3), 245-254.

Cancer, C. G. O. H. F. i. B. (2002). Breast cancer and breastfeeding: collaborative reanalysis of individual data from 47 epidemiological studies in 30 countries, including 50302 women with breast cancer and 96973 women without the disease. The Lancet, 360(9328), 187-195.

Cancer, C. G. o. H. F. i. B. (2012). Menarche, menopause, and breast cancer risk: individual participant metaanalysis, including 118964 women with breast cancer from 117 epidemiological studies. The Lancet oncology, 13(11), 1141-1151.

Casey, P. M., Cerhan, J. R., \& Pruthi, S. (2008). Oral contraceptive use and the risk of breast cancer. Paper presented at the Mayo Clinic Proceedings.

Cauley, J. A., Gutai, J. P., Kuller, L. H., LeDonne, D., \& Powell, J. G. (1989). The epidemiology of serum sex hormones in postmenopausal women. American Journal of Epidemiology, 129(6), 1120-1131.

Collaborative, G. (1996). Breast cancer and hormonal contraceptives: further results. Collaborative Group on Hormonal Factors in Breast Cancer. Contraception, 54, 1S-106S.

Cui, Y., Miller, A. B., \& Rohan, T. E. (2006). Cigarette smoking and breast cancer risk: update of a prospective cohort study. Breast Cancer Research and Treatment, 100(3), 293-299.

Esposito, K., Chiodini, P., Colao, A., Lenzi, A., \& Giugliano, D. (2012). Metabolic syndrome and risk of cancer $A$ 
systematic review and meta-analysis. Diabetes Care, 35(11), 2402-2411.

Fair, A. M., \& Montgomery, K. (2009). Energy balance, physical activity, and cancer risk Cancer epidemiology (pp. 57-88): Springer.

Frank, T. S., Manley, S. A., Olopade, O. I., Cummings, S., Garber, J. E., Bernhardt, \& et al. (1998). Sequence analysis of BRCA1 and BRCA2: correlation of mutations with family history and ovarian cancer risk. Journal of Clinical Oncology, 16(7), 2417-2425.

Friedenreich, C. M. (2001). Physical activity and cancer prevention from observational to intervention research. Cancer Epidemiology Biomarkers \& Prevention, 10(4), 287-301.

General, S. (2014). The Health consequences of smoking-50 years of progress: A report of the surgeon general. Reports of the Surgeon General. Atlanta (GA).

Glade, M. J. (2008). World Cancer Research Fund/American Institute for Cancer ResearchFood, Nutrition, Physical Activity and the Prevention of Cancer: A Global Perspective 2007 American Institute for Cancer ResearchWashington, D. CISBN: 978-0-97225222-5. Nutrition, 24(4), 393-398.

Golubicic, I., Borojevic, N., \& Pavlovic, T. (2007). Risk factors for breast cancer: is ionizing radiation among them? Journal of BU ON.: Official Journal of the Balkan Union of Oncology, 13(4), 487-494.

Goodwin, P. J., Ennis, M., Pritchard, K. I., Trudeau, M. E., Koo, J., Madarnas, Y., Hood, N. (2002). Fasting insulin and outcome in early-stage breast cancer: results of a prospective cohort study. Journal of Clinical Oncology, 20(1), 42-51.

Grodin, J., Siiteri, P., \& MacDonald, P. (1973). Source of Estrogen Production in Postmenopausal Women 1. The Journal of Clinical Endocrinology \& Metabolism, 36(2), 207-214.

Jiralerspong, S. \& Goodwin, P. J. (2016). Obesity and breast cancer prognosis: Evidence, challenges, and opportunities. J Clin Oncol 34(35), 4203-4216.

Hamajima, N., Hirose, K., Tajima, K., Rohan, T., Calle, E., Heath Jr, C., \& et al. (2002). Alcohol, tobacco and breast cancer--collaborative reanalysis of individual data from 53 epidemiological studies, including 58,515 women with breast cancer and 95,067 women without the disease. British Journal of Cancer, 87(11), 1234-1245.

Harvie, M., \& Howell, A. (2006). Energy balance adiposity and breast cancer-energy restriction strategies for breast cancer prevention. Obesity Reviews, 7(1), 3347.

Hiatt, R. A., Porco, T. C., Liu, F., Balke, K., Balmain, A., Barlow, J., \& et al. (2014). A multilevel model of postmenopausal breast cancer incidence. Cancer Epidemiology Biomarkers \& Prevention, 23(10), 2078-2092.

http://www.ncbi.nIm.nih.gov/pubmedhealth/ PMH0032634/

Huang, Z., Hankinson, S. E., Colditz, G. A., Stampfer, M. J., Hunter, D. J., Manson, \& J. E. (1997). Dual effects of weight and weight gain on breast cancer risk. JAMA, 278(17), 1407-1411.

Kaaks, R. (1996). Nutrition, hormones, and breast cancer: is insulin the missing link? Cancer Causes \& Control, 7(6), 605-625.

Kaminska, M., Ciszewski, T., Lopacka-Szatan, K., Miotla, P., \& Staroslawska, E. (2015). Breast cancer risk factors. Prz Menopauzalny, 14(3), 196-202. doi:10.5114/ pm.2015.54346

Key, T., Appleby, P., Barnes, I., \& Reeves, G. (2002). Endogenous sex hormones and breast cancer in postmenopausal women: reanalysis of nine prospective studies. Journal of the National Cancer Institute, 94(8), 606-616.

Land, C. E., Tokunaga, M., Koyama, K., Soda, M., Preston, D. L., Nishimori, I., \& Tokuoka, S. (2003). Incidence of female breast cancer among atomic bomb survivors, Hiroshima and Nagasaki, 1950-1990. Radiation Research, 160(6), 707-717.

Land, S. R., Liu, Q., Wickerham, D. L., Costantino, J. P., \& Ganz, P. A. (2014). Cigarette smoking, physical activity, and alcohol consumption as predictors of cancer incidence among women at high risk of breast cancer in the NSABP P-1 Trial. Cancer Epidemiology Biomarkers \& Prevention, 23(5), 823-832.

Li, C. I. (2010). Breast cancer epidemiology: Springer.

Ma, H., Hill, C. K., Bernstein, L., \& Ursin, G. (2008). Lowdose medical radiation exposure and breast cancer risk in women under age 50 years overall and by estrogen and progesterone receptor status: results from a case-control and a case-case comparison. Breast Cancer Research and Treatment, 109(1), 7790.

Macacu, A., Autier, P., Boniol, M., \& Boyle, P. (2015). Active and passive smoking and risk of breast cancer: a meta-analysis. Breast Cancer Research and Treatment, 154(2), 213-224.

Marmot, M., Atinmo, T., Byers, T., Chen, J., Hirohata, T., \& Jackson, A. (2007). Food, nutrition, physical activity, and the prevention of cancer: A global perspective.

Nelson, L. R., \& Bulun, S. E. (2001). Estrogen production and action. Journal of the American Academy of Dermatology, 45(3), S116-S124.

Ong, K. R., Sims, A. H., Harvie, M., Chapman, M., Dunn, W. B., Broadhurst, D., \& Clarke, R. B. (2009). Biomarkers of dietary energy restriction in women at increased 
risk of breast cancer. Cancer Prevention Research, 2(8), 720-731.

Pasanisi, P., Berrino, F., De Petris, M., Venturelli, E., Mastroianni, A., \& Panico, S. (2006). Metabolic syndrome as a prognostic factor for breast cancer recurrences. International Journal of Cancer, 119(1), 236-238.

Pharoah, P. D., Day, N. E., Duffy, S., Easton, D. F., \& Ponder, B. A. (1997). Family history and the risk of breast cancer: A systematic review and meta-analysis. International Journal of Cancer, 71(5), 800-809.

Pike, M., Krailo, M., Henderson, B., Duke, A., \& Roy, S. (1983). Breast cancer in young women and use of oral contraceptives: possible modifying effect of formulation and age at use. The Lancet, 322(8356), 926-929.

Potischman, N., Christine, A., Swanson, P. S., \& Hoover, R. N. (1996). Reversal of relation between body mass and endogenous estrogen concentrations with menopausal status. Breast Cancer, 13, 15.

Renehan, A. G., Tyson, M., Egger, M., Heller, R. F., \& Zwahlen, M. (2008). Body-mass index and incidence of cancer: a systematic review and meta-analysis of prospective observational studies. The Lancet, 371(9612), 569578.

Roberts, S. (2010). Clinical Nutrition for Oncology Patients: Jones \& Bartlett Publishers.

Ronco, A. L. (2007). Epidemiología nutricional del cáncer de mama: Academia NAcional de Medicina del Uruguay.

Ronco, A. L., \& De Stéfani, E. (2011). Nutritional epidemiology of breast cancer: Springer Science \& Business Media.

Ronco, A. L., \& De Stéfani, E. (2012). Nutritional Epidemiology of Breast Cancer.

Shi, J., Zhang, M., Li, L., Holman, C., Chen, J., Teng, Y., \& Liu, Y. (2010). Body mass index and its change in adulthood and breast cancer risk in China. Asian Pac J Cancer Prev, 11(5), 1213-1218.

Smith-Warner, S. A., Spiegelman, D., Yaun, S.-S., van den Brandt, P. A., Folsom, A. R., Goldbohm, R. A., \& Marshall, J. R. (1998). Alcohol and breast cancer in women: a pooled analysis of cohort studies. JAMA, 279(7), 535-540.

Suzuki, R., Orsini, N., Saji, S., Key, T. J., \& Wolk, A. (2009). Body weight and incidence of breast cancer defined by estrogen and progesterone receptor status-A meta-analysis. International Journal of Cancer, 124(3), 698-712.

Sweeney, C., Blair, C. K., Anderson, K. E., Lazovich, D., \& Folsom, A. R. (2004). Risk factors for breast cancer in elderly women. American Journal of Epidemiology, $160(9), 868-875$.
Tarver, T. (2012). Cancer Facts \& Figures 2012. American Cancer Society (ACS) Atlanta, GA: American Cancer Society, 2012. 66 p., pdf. Available from. Journal of Consumer Health on the Internet, 16(3), 366-367.

Thompson, H. J., Zhu, Z., \& Jiang, W. (2004). Weight control and breast cancer prevention: are the effects of reduced energy intake equivalent to those of increased energy expenditure? The Journal of Nutrition, 134(12), 3407S-3411S.

Toniolo, P. G., Levitz, M., Zeleniuch-Jacquotte, A., Banerjee, S., Koenig, K. L., Shore, R. E., Pasternack, B. S. (1995). A prospective study of endogenous estrogens and breast cancer in postmenopausal women. Journal of the National Cancer Institute, 87(3), 190-197.

Trichopoulos, D., MacMahon, B., \& Cole, P. (1972). Menopause and breast cancer risk. Journal of the National Cancer Institute, 48(3), 605-613.

Van den Brandt, P. A., Spiegelman, D., Yaun, S.-S., Adami, H.-O., Beeson, L., Folsom, A. R., Kushi, L. (2000). Pooled analysis of prospective cohort studies on height, weight, and breast cancer risk. American Journal of Epidemiology, 152(6), 514-527.

Verheus, M., Peeters, P. H., Rinaldi, S., Dossus, L., Biessy, C., Olsen, A., Clavel-Chapelon, F. (2006). Serum C-peptide levels and breast cancer risk: Results from the European prospective investigation into cancer and nutrition (EPIC). International Journal of Cancer, 119(3), 659-667.

Westhoff, C. L. (1999). Breast cancer risk: perception versus reality. Contraception, 59(1), 25-28.

Wu, Y., Zhang, D., \& Kang, S. (2013). Physical activity and risk of breast cancer: a meta-analysis of prospective studies. Breast Cancer Research and Treatment, 137(3), 869-882.

Yung, R. L. \& Ligibel, J. A. (2016). Obesity and breast cancer: risk, outcomes, and future considerations. Clin Adv Hematol Oncol 14(10), 790-797. 
